\title{
Management of acute rhinosinusitis in Danish general practice: a survey
}

This article was published in the following Dove Press journal:

Clinical Epidemiology

5 July 2011

Number of times this article has been viewed

\section{Jens Georg Hansen}

Department of Clinical Epidemiology, Aarhus University Hospital and Aalborg Hospital, Aalborg, Denmark
Correspondence: Jens Georg Hansen Department of Clinical Epidemiology, Aarhus University Hospital and Aalborg Hospital, Aalborg, Denmark

Tel +4521645867

Fax +4599326914

Email jensgeorg@dadlnet.dk
Purpose: To evaluate whether the ongoing debate over diagnostic problems and treatment choices for acute rhinosinusitis has had any influence on the management of the disease.

Methods: We randomly selected 300 Danish general practitioners (GPs) from the files of the Research Unit for General Practice at Aarhus University. Invitations to participate and a questionnaire were sent to the GPs by mail.

Results: A total of 149 (49\%) GPs answered the questionnaire. When asked about symptoms, the highest priority was given to sinus pain and signs of tenderness. The most frequent examinations were objective examination of the ear-nose-throat (ENT), palpation of the maxillofacial area, and C-reactive protein point-of-care testing (or CRP rapid test). Nearly all GPs prescribed local vasoconstrictors, and in $70 \%$ of cases, antibiotics were prescribed. Phenoxymethylpenicillin was the preferred antibiotic. Use of the CRP rapid test, years in practice, or employment in an ENT department did not have a significant impact on the diagnostic certainty and antibiotic prescribing rate.

Conclusion: The clinical diagnoses are based on a few symptoms, signs, and the CRP rapid test. Other examinations, including imaging techniques, are seldom used. Phenoxymethylpenicillin is the preferred antibiotic, and the GPs' diagnostic certainty was $70 \%$.

Keywords: general practice, acute rhinosinusitis, diagnosis, treatment, antibiotic

\section{Introduction}

Acute sinusitis is a common disease in family practice. The cause is either bacterial (purulent sinusitis) or viral (serous sinusitis), and it is a challenge for the general practitioner (GP). ${ }^{1-5}$ Acute sinusitis is defined as inflammation of the paranasal sinuses lasting no more than 12 weeks. Because inflammation of the sinus mucosa is accompanied by inflammation of the nasal mucosa, the disease is also called acute rhinosinusitis. ${ }^{6}$ The diagnosis is based primarily on clinical examination. According to Fokkens et al, ${ }^{6}$ acute rhinosinusitis is now defined as sudden onset of two or more symptoms, one of which should be either nasal blockage/obstruction/congestion or nasal discharge (anterior/posterior nasal drip), \pm facial pain/pressure, \pm reduction or loss of smell for $<12$ weeks. Many other symptoms and signs have also been described in the literature. ${ }^{7-10}$ The majority of published studies were carried out in select groups of patients in ear-nose-throat (ENT) clinics, but over the past few years papers have also been published based on family practice. , $^{1,2,10-12}$ The challenge is to distinguish between purulent rhinitis and purulent sinusitis. ${ }^{5,13,14}$ Purulent secretion from the sinuses can only be documented by sinus aspiration, but sinus aspiration cannot be performed in family practice because GPs are not trained in this technique. Use of plain radiography, 
ultrasonography, computed tomography, and magnetic resonance may also be of value but, again, are not available in general practice. Several studies have confirmed that the diagnosis of sinusitis is difficult and that this clinical insecurity is a problem. Several years ago, we published a paper investigating how Danish GPs weigh symptoms, clinical findings, and use paraclinical investigations when diagnosing acute sinusitis in adults. ${ }^{15}$ Since then, a debate has been ongoing in the literature regarding diagnostic problems and the choice of treatment. ${ }^{16-21}$ The aim of the present study was to evaluate whether this debate has had any influence on the management of acute rhinosinusitis by Danish GPs.

\section{Materials and methods}

A total of 300 Danish GPs were randomly selected from the files of the Research Unit for General Practice at Aarhus University. Invitations to participate and a questionnaire were sent by mail on March 1, 2011. One reminder was sent by mail 1 month later. The questions were related to the topics in Tables 1-4. The GPs were also asked what kind of antibiotics they prescribed and the main reason for prescribing antibiotics, how many years they had been working as a GP, if they had worked in an ENT department at any time during their education, and the GP's assessment of whether he/she believed their diagnosis was correct.

\section{Statistical analysis}

To evaluate the GPs' prioritization of symptoms, signs, use of examinations, and treatment, we calculated the median value and $95 \%$ confidence interval (95\% CI) for each question. To analyze the use of C-reactive protein (CRP) point-of-care testing via the CRP rapid test, employment in an ENT department, or the GP's assessment of the diagnosis being accurate, we used the Mann-Whitney test. Possible nonlinear relationships with the number of years as a GP were

Table I Prioritization of symptoms by general practitioners when diagnosing acute rhinosinusitis. Points $\mathrm{I}-10$

\begin{tabular}{lll}
\hline Symptoms & Median & $\mathbf{9 5 \%} \mathbf{C l}$ \\
\hline Sinus pain & 9 & $9-10$ \\
Pain bending forward & 8 & $8-9$ \\
Maxillary toothache & 7 & $6-8$ \\
Preceding cold & 7 & $6-8$ \\
Unilateral symptoms & 5 & $5-5$ \\
Self-reported previous sinusitis & 5 & $5-5$ \\
Nasal congestion & 5 & $5-5$ \\
Cacosmia & 2 & $2-3$ \\
Reduced sense of smell & 2 & $2-3$ \\
Cough & 2 & $1-2$ \\
\hline
\end{tabular}

Abbreviation: $\mathrm{Cl}$, confidence interval.
Table 2 Prioritization of signs by general practitioners when diagnosing acute rhinosinusitis. Points $1-10$

\begin{tabular}{lll}
\hline Signs & Median & $\mathbf{9 5 \%} \mathbf{C l}$ \\
\hline Sinus tenderness & 8 & $8-8$ \\
Edema over the sinuses & 8 & $7-8$ \\
Tenderness upon tapping the maxillary teeth & 6 & $5-7$ \\
Purulent pharyngeal discharge & 6 & $5-6$ \\
Temperature $>38^{\circ} \mathrm{C}$ & 5 & $5-6$ \\
Sinus tenderness, unilateral & 5 & $4-5$ \\
Purulent nasal discharge, unilateral & 5 & $4-5$ \\
Sinus tenderness, bilateral & 5 & $4-5$ \\
Purulent nasal discharge, bilateral & 4 & $3-5$ \\
Swollen inflamed turbinates & 2 & $2-3$ \\
\hline
\end{tabular}

Abbreviation: $\mathrm{Cl}$, confidence interval.

investigated using fractional polynomials. ${ }^{22}$ The significance level was set at 5\%. Statistical analyses were performed using STATA (v 11; StataCorp LP, College Station, TX).

\section{Results}

A total of 149 (49\%) GPs answered the questionnaire. Tables 1 and 2 show the GPs prioritized symptoms and signs when diagnosing acute rhinosinusitis: highest priority was given to sinus pain and tenderness. Table 3 shows the distribution of the different examinations used by the GPs. The most frequent examinations were objective ENT examination, palpation of the maxillofacial area, and the CRP rapid test. Table 4 shows the preferred treatment. Nearly all GPs prescribe local vasoconstrictors, and in 70\% of cases (95\% CI: 50-80) antibiotics were prescribed. Phenoxymethylpenicillin was the preferred antibiotic for the majority (90\%) of patients treated $(95 \%$ CI: 82-90). Most of the remaining 10\% of patients were treated with macrolide (95\% CI: 5-10), as other antibiotics were seldom used. Nasal steroid was prescribed in $20 \%$ of patients (95\% CI: 10-30). Few patients were referred to specialists. The GPs had, on average, worked in primary care for 20 years

Table 3 Indications of how often general practitioners use the following examinations when diagnosing acute rhinosinusitis. Range 0\%-100\%

\begin{tabular}{|c|c|c|}
\hline Examination & Median & $95 \% \mathrm{Cl}$ \\
\hline Objective examination of ear-nose-throat & 100 & $100-100$ \\
\hline Palpation of the maxillofacial area & 93 & $90-100$ \\
\hline Measurement of CRPa & 75 & $60-80$ \\
\hline Measurement of leukocytes & 0 & $0-0$ \\
\hline Sampling from pharynx & 0 & $0-0$ \\
\hline Measurement of ESR ${ }^{b}$ & 0 & $0-0$ \\
\hline X-ray & 0 & $0-0$ \\
\hline Sampling from the nose cavity & 0 & $0-0$ \\
\hline Ultrasonography & 0 & $0-0$ \\
\hline
\end{tabular}

Notes: ${ }^{\mathrm{C} C}$-reactive protein, point-of care test; ${ }^{\mathrm{b}} \mathrm{Erythrocyte}$ sedimentation rate. Abbreviation: $\mathrm{Cl}$, confidence interval. 
Table 4 Indications of how often general practitioners use the following treatments when they have diagnosed acute rhinosinusitis. Range 0\%-100\%

\begin{tabular}{lll}
\hline Treatment & Median & $\mathbf{9 5 \%} \mathbf{~ C l}$ \\
\hline Local vasoconstrictor & 90 & $80-100$ \\
Analgesic & 75 & $54-80$ \\
Antibiotic & 70 & $50-80$ \\
Nasal irrigation & 25 & $10-45$ \\
Nasal steroid & 20 & $10-30$ \\
Heat treatment & 0 & $0-0$ \\
Antihistamine & 0 & $0-0$ \\
Primarily referral to ENT specialist & 0 & $0-0$ \\
None & 0 & $0-0$ \\
\hline
\end{tabular}

Abbreviation: $\mathrm{Cl}$, confidence interval.

(95\% CI: 16-20). Twenty-eight (19\%) of the GPs had been employed in an ENT department during their education. The GPs estimated their own diagnostic certainty as being 70\% (95\% CI: 60-75). The analyses showed that use of the CRP rapid test, number of years in practice, and employment in an ENT department did not have a significant impact on the diagnostic certainty and antibiotic prescribing rate. The analysis of the GPs' own explanations and reasons for prescribing antibiotics showed that the patient's clinical condition had a strong influence on the prescribing rate.

\section{Discussion}

Acute rhinosinusitis is a very frequent diagnosis in family practice. Clinical diagnosis is difficult because the signs and symptoms of acute bacterial rhinosinusitis and prolonged viral upper respiratory infection are similar. ${ }^{1,3}$ Only $53 \%$ of patients suspected of having acute maxillary sinusitis have purulence in the sinus secretions obtained by antral puncture. ${ }^{1}$ The predominant sinus diagnostics and treatment in general practice concerns acute rhinosinusitis in adults. ${ }^{1,2,6,10-12}$ We were not able to demonstrate an association between the years of practice, employment in an ENT department any time during the GP's education, or use of the CRP rapid test when diagnosing acute rhinosinusitis and the antibiotic prescribing rate or diagnostic certainty. In contrast, a Dutch study showed that the longer a GP had practiced, the more frequently they prescribed antibiotics. ${ }^{23}$ The crucial symptom causing a patient to see the GP was reported to be pain above the maxillae, which was also found in this study. Pressure tenderness above the sinuses, increased pain when bending forward, pain in the upper teeth, change in the sense of smell, a general feeling of being unwell, purulent secretion from the nose, and worsening symptoms after initial improvement (double sickening) are also suggested as being associated with the diagnosis. ${ }^{2,3}$
This study showed a different pattern because the clinical diagnosis is mainly based on a few symptoms, signs, and use of the CRP rapid test, whereas the use of other examinations, including imaging techniques, seldom occurs. This finding corresponds well with other published studies. ${ }^{2,3}$ The CRP rapid test has been used in Danish family practice since 1999. During the years, the number of tests has gradually increased to nearly $13 \%$ per year. In 2010 , the total number of tests performed was 1.1 million. An increased CRP level on the rapid test is an indicator of bacterial infection, and the CRP rapid test has been shown to be particularly useful for diagnosing bacterial sinusitis in general practice, including for prescribing antibiotics. ${ }^{1,2,23-25}$ The use of phenoxymethylpenicillin as a first choice antibiotic for acute bacterial rhinosinusitis is in accordance with Scandinavian convention and has not changed over the years. Several studies have shown that use of the CRP rapid test can reduce unnecessary antibiotic prescriptions, reducing the risk of introducing bacterial resistance to antibiotics. ${ }^{21,23-25}$ Therefore, the use of the test in only $75 \%$ of the cases was surprising, as well as the use of the CRP rapid test not having any influence on the diagnostic certainty or antibiotic prescribing rate, which has been shown in other studies. ${ }^{21,23-25}$ The observation is thought provoking. The study design did not allow for detailed subgroup analyses, but one explanation might be that the GPs who do not use the CRP rapid test feel safer when diagnosing acute rhinosinusitis and prescribing antibiotics than the GPs who do use the CRP rapid test and because of that they find the CRP rapid test to be of little or no help. Studies looking at both GP and patient characteristics are needed in the future to explain this finding in order to optimize both diagnostic certainty and antibiotic prescriptions. The GPs estimated their own diagnostic certainty as being $70 \%$, confirming that the diagnosis is still a challenge in family practice. This percentage was the same in a survey more than 10 years $\mathrm{ago}^{15}$ and is in accordance with another study from Dutch primary health care. ${ }^{8}$

Acknowledging different strengths and weaknesses of the study is important when interpreting the results. The answers to surveys among Danish GPs are generally of excellent quality with high reproducibility. The number of Danish GPs is approximately 3600. The number of invited participants was 300 , but only $149(50 \%)$ answered the questionnaire, which is lower than expected because the usual response rate has been $66 \%$ in similar studies. I was not allowed to ask the drop-outs the reason for not answering, but I assume it was due to lack of time or interest in the research topic. The group of nonresponders and responders did not differ in regards to type of practice (group or solo) or sex. Therefore I assume that 
acute rhinosinusitis was managed similarly in the two groups. Any selection bias caused by the low response rate is thus likely to be minor. The results showed that the GPs' management of acute rhinosinusitis corresponded well with results from other similar studies. Unfortunately, the study design did not allow us to perform a more specific analysis of the use of the CRP rapid test. It is surprising that the use of the CRP rapid test did not have any significant impact on diagnosis, prescription, or clinical certainty. The test has a strong influence on the rate of prescribing antibiotics, because increasing CRP value is a strong indicator of bacterial infection, ${ }^{24}$ but in the survey the GPs were only asked how often they used the CRP rapid test, not the precise value. The survey confirmed that acute rhinosinusitis is still a challenge for GPs, despite several studies from general practice being published in recent years.

\section{Acknowledgments}

I thank Lars Oddershede of Aalborg University for careful data entry and statistical assistance, in cooperation with Søren Lundby-Christensen Aalborg Hospital. I thank the Research Unit for General Practice at Aarhus University for providing the GPs' mailing addresses.

\section{Disclosure}

The author reports no conflicts of interest for this work.

\section{References}

1. Hansen JG, Schmidt H, Rosborg J, Lund E. Predicting acute maxillary sinusitis in a general practice population. BMJ. 1995;311(6999): 233-236.

2. Lindbæk M, Hjortdahl P. The clinical diagnosis of acute purulent sinusitis in general population - a review. Br J Gen Pract. 2002;52(479): 491-495.

3. Scheid DC, Hamm RM. Acute bacterial rhinosinusitis in adults: part 1. Evaluation. Am Fam Physician. 2004:70(9):1685-1692.

4. Williams JW, Simel DL, Roberts L, Samsa GP. Clinical evaluation for sinusitis. Making the diagnosis by history and physical examination. Ann Intern Med. 1992;117(9):705-710.

5. Williams JW, David L, Simel DL. Does this patient have sinusitis? JAMA. 1993;270(10):1242-1246.

6. Fokkens WJ, Lund V, Mullol J, et al. European position paper on rhinosinusitis and nasal polyps 2007. A summary for otorhinolaryngologists. Rhinology 2007;45(2):97-101.

7. Druce HM. Diagnosis of sinusitis in adults: history, physical examination. nasal cytology, echo, and rhinoscope. J Allergy Clin Immunol. 1992; 90(3 Pt 2):436-441.

Clinical Epidemiology

\section{Publish your work in this journal}

Clinical Epidemiology is an international, peer-reviewed, open access journal focusing on disease and drug epidemiology, identification of risk factors and screening procedures to develop optimal preventative initiatives and programs. Specific topics include: diagnosis, prognosis, treatment, screening, prevention, risk factor modification, systematic

Submit your manuscript here: http://www.dovepress.com/clinical-epidemiology-journal
8. Van Duijn NP, Brouwer HJ, Lamberts H. Use of symptoms and signs to diagnose maxillary sinusitis in general practice: comparison with ultrasonography. BMJ. 1992;305(6855):684-687.

9. Berg O, Carenfelt C. Analysis of symptoms and signs in the maxillary sinus empyema. Acta Otolaryngol. 1988;105(3-4):343-349.

10. Sande MA, Gwaltney JM. Acute community-acquired bacterial sinusitis: continuing challenges and current management. Clin Infect Dis. 2004;39(Suppl 3):S151-S158.

11. Blomgren K, Alho O-P, Ertama L, et al. Acute sinusitis: finnish clinical practice guidelines. Scan J Infect Dis. 2005;37(4):245-250.

12. Klossek J-M, Mesbah K. Presentation and treatment of acute maxillary sinusitis in general practice: a French observational study. Rhinology. 2011;49(1):84-89.

13. Berg O, Bergstedt H, Carenfelt C, Lind MG, Perols O. Discrimination of purulent from nonpurulent maxillary sinusitis. Clinical and radiographic diagnosis. Ann Otol. 1981;90(3 Pt 1):272-275.

14. Savolainen S, Ylikoski J, Jousimies-Somer H. Differential diagnosis of purulent and non-purulent acute maxillary sinusitis in young adults. Rhinology. 1989;27(1):53-61.

15. Hansen JG, Schmidt H. Diagnosis and treatment of acute sinusitis by Danish general practitioners. (English summary). Ugeskr Lager. 1994;156(13):1934-1940.

16. Hansen JG, Schmidt H, Grinsted P. Randomised, double blind, placebo controlled trial of penicillin $\mathrm{V}$ in treatment of acute maxillary sinusitis in adults in general practice. Scan J Prim Health Care. 2000; 18(1):44-47.

17. Lindbæk M, Hjortdal P, Johnsen UL. Randomised, double blind, placebo controlled trial of penicillin $\mathrm{V}$ and amoxycillin in treatment of acute sinus infections in adults. BMJ. 1996;313(7053):325-326.

18. Van Buchem FL, Knottnerus JA, Schrijnemaekers VJJ, Peter MF. Primary-care-based randomised placebo-controlled trial of antibiotic treatment in acute maxillary sinusitis. Lancet. 1997;349(9053): 683-687.

19. De Sutter A, Lemiengre M, Van Maele G, et al. Predicting prognosis and effect of antibiotic treatment in rhinosinusitis. Ann Fam Med. 2006;4(6):486-493.

20. Williamson IG, Rumbsby K, Benge S, et al. Antibiotics and topical nasal steroid for treatment of acute maxillary sinusitis: a randomized controlled trial. JAMA. 2007;298(21);2487-2496.

21. Young J, De Sutter A, Merenstein D, et al. Antibiotics for adults with clinically diagnosed acute rhinosinusitis: a meta-analysis of individual patient data. Lancet. 2008;371(9616):908-914.

22. Royston P, Altman DG. Regression using fractional polynomials of continuous covariates: parsimonious modelling (with discussion). Applied Statistics. 1994;43:429-467.

23. Akkerman AE, Kuyvenhoven MM, van der Wouden JC, Verheij TJ. Prescribing antibiotics for respiratory tract infections by GPs: management and prescriber characteristics. Br J Gen Pract. 2005;55(511): 114-118.

24. Bjerrum L, Gahrn-Hansen B, Munck AP. C-reactive protein measurement in general practice may lead to lower antibiotic prescribing for sinusitis. Br J Gen Pract. 2004;54(506):659-662.

25. QCals JW, Schot MJ, de Jong SA, Dinant GJ, Hopstaken RM. Point-of-care C-reactive protein testing and antibiotic prescribing for respiratory tract infections: a randomized controlled trial. Ann Fam Med. 2010;8(2):124-133.

reviews, risk \& safety of medical interventions, epidemiology \& biostatical methods, evaluation of guidelines, translational medicine, health policies \& economic evaluations. The manuscript management system is completely online and includes a very quick and fair peer-review system, which is all easy to use. 